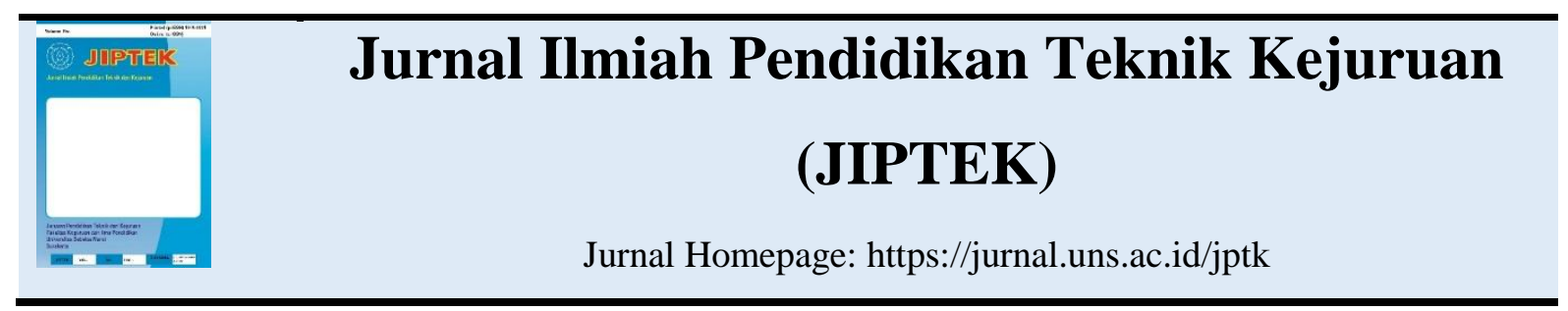

\title{
STUDI KELAYAKAN TRAINER JARINGAN KOMPUTER SEBAGAI MEDIA BELAJAR PADA PRAKTIKUM JARINGAN KOMPUTER DASAR
}

\author{
Agustina Dyah Pratiwi ${ }^{1}$, Puspanda Hatta ${ }^{2}$, Agus Efendi ${ }^{3}$ \\ 1, 2, ${ }^{3}$ Program Studi Pendidikan Teknik Informatika dan Komputer, Fakultas Keguruan dan \\ Ilmu Pendidikan, Universitas Sebelas Maret Surakarta \\ Email: hatta.puspanda@staff.uns.ac.id
}

\begin{abstract}
ABSTRAK
Jaringan komputer merupakan mata kuliah yang umum terdapat dalam kurikulum pendidikan tingi bidang teknologi informasi. Pada mata kuliah jaringan komputer, mahasiswa dituntut memiliki kompetensi dalam mengoperasikan perangkat keras jaringan komputer. Pada umumnya, pembelajaran praktik untuk melatih ketrampilan motorik pada jaringan komputer selama ini hanya menggunakan software simulasi. Pada umumnya, mahasiswa belum memiliki ketrampilan dalam mengoperasikan perangkat jaringan secara langsung pada tingkat dasar ini. Pada penelitian ini dibuat sebuah media belajar praktik untuk jaringan komputer dasar dalam bentuk perangkat keras trainer. Trainer tersebut digunakan sebagai media belajar praktik untuk mengoperasikan network device secara nyata. Penelitian ini juga bertujuan untuk menguji tingkat kelayakan trainer jaringan komputer ketika digunakan dalam perkuliahan. Model pengembangan yang digunakan untuk membuat trainer ini menggunakan model pengembangan Alessi dan Trollip. Hasil validasi dari ahli media dari segi kelayakan perangkat media belajar menunjukkan tingkat kelayakan trainer ini sebagai media belajar praktikum sebesar $80,7 \%$. Sedangkan hasil validasi dari praktisi jaringan komputer menunjukkan bahwa tingkat kelayakan materi trainer jaringan ini sebesar $89,4 \%$ jika digunakan sebagai suplemen untuk pembelajaran jaringan komputer dasar.
\end{abstract}

Kata kunci: Jaringan Komputer, Praktikum, Trainer, Simulasi

\begin{abstract}
Computer networking is a common course contained in high education curriculum in the field of information technology. In computer network courses, students are required to have competence in operating computer network hardware. In general, practical learning to train motor skills on computer networks has been using simulation software. In general, students do not have the skills to operate network devices directly at this basic level. In this study, a practical learning media for basic computer network in the form of hardware trainer. Trainers are used as a medium of learning practices to operate a real network device. This study also aims to test the feasibility level of computer network trainers when used in lectures. The development model used to create this trainer uses the Alessi and Trollip development model. Validation results from media experts in terms of feasibility learning media devices show the feasibility level of this trainer as a learning media practicum of $80.7 \%$. While the validation results from computer network practitioners showed that the feasibility level of this network trainer material is $89.4 \%$ if used as a supplement for basic computer network learning.
\end{abstract}




\section{PENDAHULUAN}

Media pembelajaran berbasis komputer dikembangkan dalam berbagai variasi bentuk, mulai dari media pembelajaran berbasis desktop, android, simulator, augmented reality hingga mengintegrasikan komponen - komponen computer dalam bentuk alat peraga atau trainer. Beberapa media pembelajaran diaplikasikan untuk membantu siswa memahami konsep abstrak pada sains. Konsep abstrak pada ilmuilmu teknik dan sains yang canggih dan sulit diajarkan menggunakan media tradisional dapat diterapkan dengan mudah melalui media berbasis teknologi (Rahman, 2015).

Salah satu dari mata pelajaran di SMK yang menerapkan berbagai media pembelajaran adalah jaringan komputer (Pernanda,2018). Pada tingkat dasar, jaringan komputer di SMK mempelajari tentang teknologi TCP/IP, media transmisi data, pengalamatan internet protocol (IP), subnetting, IP routing, layanan DHCP, dan network address translation (Samad, 2017). Berdasarkan hasil studi pendahuluan, saat ini pembelajaran jaringan komputer di SMK pada umumnya memanfaatkan aplikasi simulasi jaringan yaitu Cisco Packet Tracer (Ampriliambudi, 2017). Pemanfaatan aplikasi ini membantu mahasiswa memahami konsep jaringan komputer secara teoritis.

Sekalipun telah diterapkan media pembelajaran berbasis simulator, beberapa materi pembelajaran yang berkaitan dengan konfigurasi peralatan pada layer fisik tetap membutuhkan alat peraga untuk memudahkan penyampaian konsep atau materi kepada peserta didik. Simulator tidak dapat memfasilitasi kebutuhan siswa untuk berinteraksi dengan perangkat jaringan yang bekerja pada layer fisik seperti pengkabelan, interfacing, pointing, dan troubleshooting. Kemampuan hardskill tersebut membutuhkan perangkat jaringan riil yang dibangun dalam satu paket sesuai dengan kebutuhan minimal jaringan LAN.

Kerucut Pengalaman Edgar Dale mengemukakan bahwa pembelajaran dengan memanfaatkan tiruan pengalaman yang diberi bentuk seperti model, benda tiruan, atau simulasi dapat memberikan pengalaman yang lebih nyata kepada peserta didik (Lee, S. J., \& Reeves, T. C, 2017). Kekurangan dari penggunaan simulator ini adalah mahasiswa tidak mempunyai ketrampilan psikomotorik untuk mengoperasikan perangkat jaringan secara riil. Diperlukan sebuah media pembelajaran jaringan berbentuk trainer agar mahasiswa mempunyai keahlian dalam pengoperasian alat-alat jaringan.

Untuk mengatasi permasalahan tersebut, dalam penelitian ini dikembangkan sebuah alat peraga (trainer) jaringan komputer. Trainer tersebut memfasilitasi siswa mempelajari mempelajari dasar-dasar konfigurasi jaringan dengan alat jaringan yang sebenarnya. Siswa akan mampu berinteraksi dengan perangkat jaringan yang bekerja pada layer fisik dengan menggunakan trainer ini. Tujuan dari penelitian ini adalah untuk mengembangkan media pembelajaran trainer jaringan komputer dan buku manual yang akan digunakan untuk praktikum. Penelitian ini juga bertujuan untuk menguji kelayakan trainer jaringan komputer 
dari segi kelayakan produk dan kelayakan substansi materi pada buku panduannya.

\section{LANDASAN TEORI}

\section{A. Jaringan Komputer}

Jaringan komputer adalah jaringan yang terdiri dari setidaknya dua komputer yang terhubung ke media sehingga komputer dapat saling berbagi sumber daya dan saling berkomunikasi. Ada berbagai jenis jaringan seperti Personal Area Network (PAN), Local Area Network (LAN), Metropolitan Area Network (MAN), Campus Area Network (CAN), Storage Area Network (SAN) dan Wide Area Network (WAN) (Arifin, 2005).

\section{B. Media Trainer}

Iwan (2014: 109) mengemukakan bahwa pengertian trainer adalah alat (benda) yang digunakan untuk memperagakan fakta, konsep, prinsip atau prosedur tertentu agar tampak lebih nyata/ konkrit. Pada beberapa materi belajar, trainer dibutuhkan untuk menjelaskan konsep yang rumit dan membutuhkan praktik secara langsung untuk memahami. Berdasarkan hasil penelitian Arvin (2016) menunjukkan bahwa pembelajaran dengan menggunakan trainer memudahkan peserta didik untuk memahami konsep, hal ini dapat diketahui dari peningkatan rata-rata hasil belajar yakni dari 57.54 menjadi 78.68 setalah pemanfaatan media trainer. Penelitian tentang pemanfaatan media trainer sebagai media pembelajaran juga dilakukan oleh Aris (2013) dengan kesimpulan bahwa pemanfaatan trainer sebagai media pembelajaran dapat meningkatkan kualitas pembelajaran sebanyak $14.9 \%$. Berdasarkan hasil dari kedua penelitian tersebut dapat disimpulkan bahwa pemanfaatan media berupa trainer atau alat peraga efektif membantu siswa dalam memahami materi sehingga dapat meningkatkan hasil belajar.

Trainer jaringan komputer dasar merupakan media pembelajaran yang berbentuk hardware. Trainer ini dibuat dengan tujuan untuk digunakan sebagai alat peraga pada praktikum mata kuliah jaringan komputer. Beberapa Materi Pokok yang menjadi dasar pembuatan trainer ini antara lain media transmisi, peralatan jaringan komputer, pengalamatan IP, subnetting, routing, konfigurasi DHCP, konfigurasi Network Address Translation dan troubleshooting.

Trainer dibuat dengan menggabungkan beberapa peralatan jaringan yang mendukung materi pokok tersebut, antara lain: Modem, Router, Switch, PoE, Monitor, Antena Omni, Antena Directional dan Media Transmisi sehingga membentuk sebuah simulator jaringan yang dapat dijadikan sebagai trainer pada praktikum.

\section{Penelitian yang relevan}

Penelitian pembuatan media trainer pernah dilakukan oleh Zukifli dan Suparmin (2015). Penelitian tersebut mengembangkan Wireless Communication Network Tools Kit dengan menggunakan Teknik Visualisasi. Trainer tersebut digunakan pada pembelajarana komunikasi nirkabel untuk perkuliahan. Trainer tersebut berfokus pada perangkat komunikasi nirkabel standar 802.xx seperti bluetooth, Wifi dan RFID. Penelitian serupa dilakukan oleh Siagian (2014) mengembangkan trainer dan modul untuk media pembelajara instrumentasi 
elektronika. Hasil penelitian menunjukkan bahwa modul dan trainer efektif untuk meningkatkan hasil belajar siswa. Kedua penelitian tersebut menunjukkan bahwa media pembelajaran dalam bentuk trainer membantu siswa pemula untuk meningkatkan keterampilan dan kemampuan mereka (Siagian, 2014).

Pembaharuan dalam penelitian ini adalah membuat media belajar untuk jaringan komputer berupa trainer yang terdiri dari perangkatperangkat jaringan komputer. Validitas dan kelayakan media trainer ini diuji oleh ahli media dan ahli materi. Uji kelayakan tersebut dirancang untuk mengetahui reliabilitas alat ketika digunakan untuk media praktikum dan untuk mengetahui kompatibilitas materi pada buku panduan media trainer ini terhadap materi-materi jaringan komputer dasar pada kurikulum teknologi informasi dana tau informatika pada perguruan tinggi.

\section{METODE PENELITIAN}

A. Model Pengembangan

Penelitian ini menggunakan metode penelitian dan pengembangan. Model pengembangan yang digunakan dalam penelitian ini adalah Alessi dan Trollip. Model pengembangan Alessi dan Trollip dibagi dalam empat tahap yaitu perencanaan, perancangan, pengembangan dan evaluasi. Setiap tahap memberi instruksi bagaimana mengembangkan media mulai dari menentukan ruang lingkup sampai cara evaluasi (Khan dan Masood, 2013).

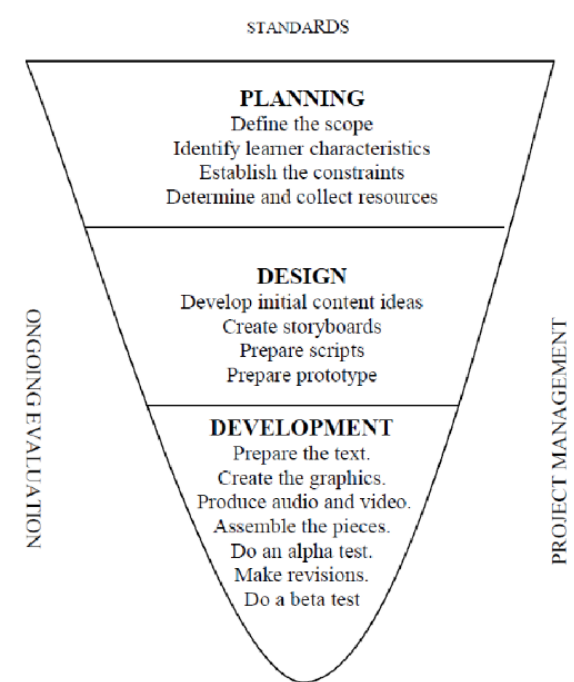

Gambar 1. Metode Alessi dan Trolip

Gambar 1 menunjukkan fase model pengembangan yang digunakan dalam model pengembangan Alessi dan Trollip, dengan penjelasan sebagai berikut :

1. Perencanaan

Menetapkan materi pembelajaran yang sesuai dengan media trainer (Por dan Fong, 2011).

\section{Perancangan}

Membuat desain fisik dan perancangan purwarupa.

\section{Pengembangan}

Realisasi desain dengan membuat bentuk fisik trainer (Por dan Fong, 2011).

\section{Evaluasi}

Proses yang konstan untuk memastikan semua standar terpenuhi pada trainer terpenuhi dan layak digunakan sebagai media belajar (Por dan Fong, 2011).

Pengumpulan data yang digunakan dalam penelitian ini adalah kajian literatur, dan wawancara. Kajian literatur digunakan untuk menemukan penelitian sebelumnya tentang pemanfaatan media trainer sebagai media belajar 
praktikum. Sedangkan wawancara digunakan untuk menentukan kebutuhan pada tahap planning dan design. Wawancara dilakukan pada sekelompok sampling yaitu mahasiswa yang mempelajari mata kuliah jaringan komputer, tenaga pengajar pengampu jaringan komputer, praktisi jaringan komputer, dan ahli media.

Hasil dari wawancara adalah mengetahui kelemahan media pembelajaran yang selama ini digunakan pada mata kuliah jaringan komputer karena hanya bersifat simulasi. Selain itu, dari hasil wawancara diperoleh data-data tentang jenis media pembelajaran dan alat yang dibutuhkan. Kuesioner digunakan untuk menguji kelayakan media pembelajaran. Pertanyaan-pertanyaan dalam kuesioner dibuat berdasarkan kriteria seleksi media pembelajaran oleh Asyhar (Asyhar, 2012). Berdasarkan kriteria yang disebutkan, aspek pengetahuan yang perlu diuji adalah kualitas pengetahuan dan relevansi pengetahuan. Sedangkan aspek media yang perlu diuji adalah presentability, efisiensi, fleksibilitas, kehandalan, kualitas, dan kesesuaian ukuran.

\section{B. Penentuan Skor}

Pada penelitian ini tiap-tiap butir kuisioner diberikan skor. Rentang skor tersebut adalah 1 sampai 5 dengan kriteria sebagai berikut :

Tabel 1. Kriteria Skor

\begin{tabular}{cc}
\hline Skor & Kriteria \\
\hline 5 & Sangat Setuju \\
4 & Setuju \\
3 & Kurang Setuju \\
2 & Tidak Setuju \\
1 & Sangat Tidak Setuju \\
\hline
\end{tabular}

Untuk mempermudah pembacaan, maka dari skor tersebut diubah menjadi bentuk nilai akhir dengan rumus sebagai berikut :

$$
\text { Nilai Akhir }=\frac{\text { Jumlah Skor } \times 100}{\text { Jumlah Pernyataan } \times 5} \times 100 \%
$$

Nilai akhir tersebut kemudian diklasifikasikan dengan kriteria sebagai berikut :

Tabel 2. Kriteria Nilai Akhir

\begin{tabular}{cc}
\hline Nilai Akhir & Kriteria \\
\hline $80,01 \%-100,00 \%$ & Sangat Layak \\
$70,00 \%-80,00 \%$ & Layak \\
$60,01 \%-70,00 \%$ & Cukup Layak \\
$50,01 \%-60,00 \%$ & Kurang \\
$<50 \%$ & Sangat Kurang \\
\hline
\end{tabular}

\section{Analisis Data}

Analisis data yang digunakan pada penelitian ini adalah Analisis Interaktif (Riduwan, 2013). Analisis Interaktif terbagi menjadi 3 tahapan :

1. Reduksi Data

Reduksi data digunakan untuk mengumpulkan data yang diperlukan dan menghilangkan data yang tidak diperlukan.

2. Penyajian data

Penyajian data dalam bentuk tabel dan melakukan langkah-langkah analisa perhitungan data.

3. Penarikan Kesimpulan

Penarikan kesimpulan dilakukan berdasarkan hasil penyajian data dan hasil analisa perhitungan data. Kesimpulan disampaikan dalam bentuk naratif berdasarkan hasil perhitungan.

\section{HASIL PENELITIAN DAN PEMBAHASAN}

\section{A. Perencanaan}

Dari hasil wawancara diketahui bahwa sebagian besar kegiatan pembelajaran jaringan komputer merupakan praktik. Siswa membutuhkan komponen jaringan nyata untuk melaksanakan praktik sehingga siswa memiliki pengalaman motorik dalam mengoperasikan komponen jaringan. Tahap perencanaan digunakan untuk 
mengetahui kebutuhan minimum trainer. Berikut ini adalah kebutuhan trainer yang disesuaikan dengan materi praktik jaringan komputer

Tabel 3. Analisis Kebutuhan Trainer

\begin{tabular}{|c|c|}
\hline Materi Praktik & Komponen \\
\hline Pengkabelan dan & UTP Cable, Cable \\
\hline Troubleshooting. & $\begin{array}{l}\text { Cutter, } \\
\text { RJ-45, Tang } \\
\text { Crimping, } \\
\text { Cable Tester, } \\
\text { Straight UTP } \\
\text { Cable dan Cross } \\
\text { UTP Cable. }\end{array}$ \\
\hline Konfigurasi dasar & Modem, Router, \\
\hline Router, Pengalamatan & Kabel UTP, \\
\hline $\begin{array}{l}\text { IP, Konfigurasi DNS, } \\
\text { NAT dan DHCP }\end{array}$ & $\begin{array}{l}\text { Switch, } \\
\text { Laptop. }\end{array}$ \\
\hline Media Transmisi & $\begin{array}{l}\text { Kabel UTP and } \\
\text { Coaxial }\end{array}$ \\
\hline $\begin{array}{l}\text { Pengenalan komponen } \\
\text { jaringan komputer } \\
\text { (network devices) }\end{array}$ & $\begin{array}{l}\text { Router, Switch, } \\
\text { Modem, PoE, dan } \\
\text { antenna nirkabel }\end{array}$ \\
\hline
\end{tabular}

Dari tabel 3 di atas dapat diketahui minimum requirements yang harus terdapat dari trainer jaringan komputer. Mahasiswa yang mengambil perkuliahan ini adalah mahasiswa yang baru mempelajari dasar-dasar jaringan komputer, sehingga mahasiswa juga memerlukan buku panduan untuk mengoperasikan perangkat jaringan yang terpasang pada trainer.

\section{B. Perancangan}

Hasil dari tahap ini adalah finalisasi terhadap dimensi dan tata letak media trainer jaringan komputer.

Tabel 4. Pengukuran Dimensi Komponen

\begin{tabular}{clcc}
\hline & Components & Width & Height \\
\hline 1. & Monitor & $35 \mathrm{~cm}$ & $25 \mathrm{~cm}$ \\
2. & Modem & $10 \mathrm{~cm}$ & $10 \mathrm{~cm}$ \\
3. & Router & $13 \mathrm{~cm}$ & $15 \mathrm{~cm}$ \\
4. & Switch & $6 \mathrm{~cm}$ & $15 \mathrm{~cm}$ \\
5. & UTP Cable & $10 \mathrm{~cm}$ & $3 \mathrm{~cm}$
\end{tabular}

Total

$74 \mathrm{~cm}$

$65 \mathrm{~cm}$

Dimensi dari trainer jaringan komputer ini diukur berdasarkan ukuran masing-masing komponen yang ditunjukkan dalam tabel 4 . Gambar 2 menunjukkan dimensi dari media trainer jaringan komputer

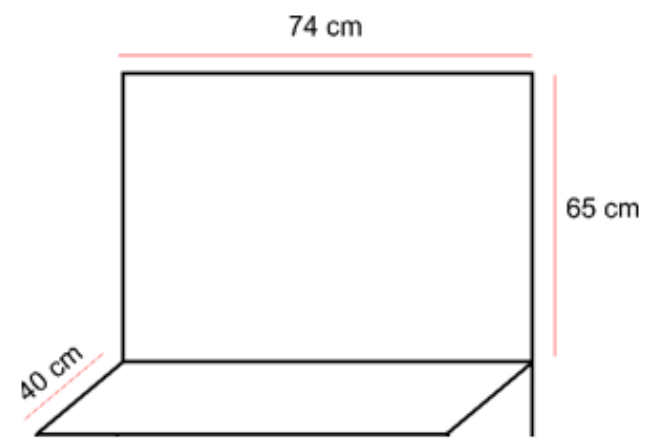

Gambar 2. Dimensi Trainer

Tata letak media trainer dibuat berdasarkan ukuran yang ditunjukkan dalam gambar 3 .

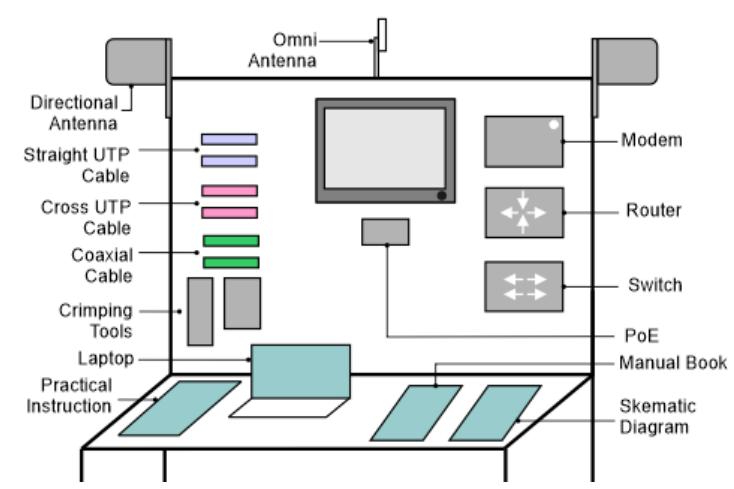

Gambar 3. Tata Letak Media Trainer

C. Tahap Pengembangan

Setiap komponen diletakkan berdasarkan tata letak yang di desain pada gambar 4. Setelah semua komponen ditempatkan, masing-masing network device dihubungkan dengan kabel UTP. 


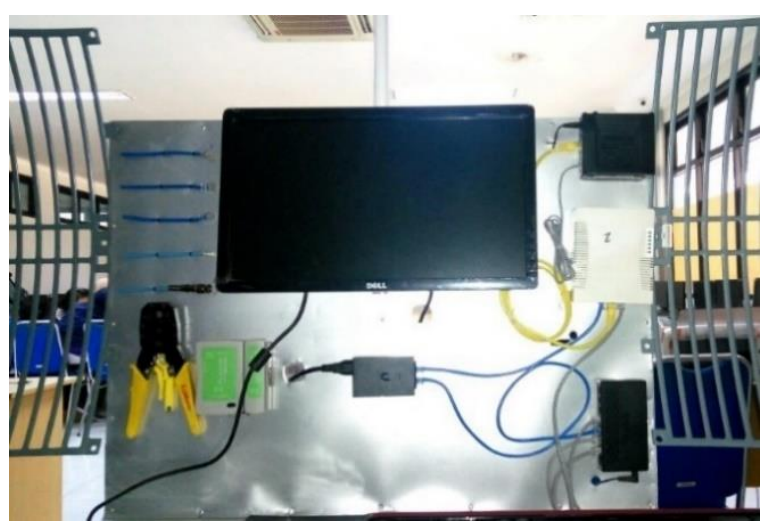

Gambar 4. Trainer Jaringan Komputer

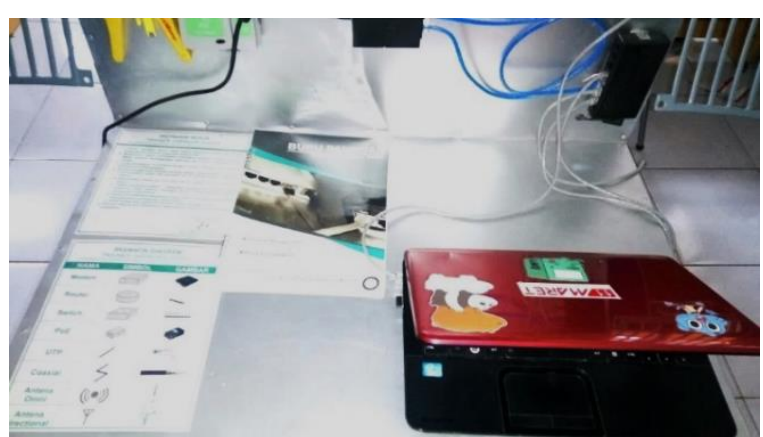

Gambar 5. Trainer Jaringan Komputer

4. Evaluasi

\section{- Uji Fungsional}

Masing-masing komponen trainer jaringan dievaluasi untuk mengetahui apakah komponen tersebut berfungsi jika pengoperasian disesuaikan dengan buku panduan penggunaan. Hasil pengujian ditunjukkan pada tabel 5 berikut ini :

Tabel 5. Hasil Uji Fungsional

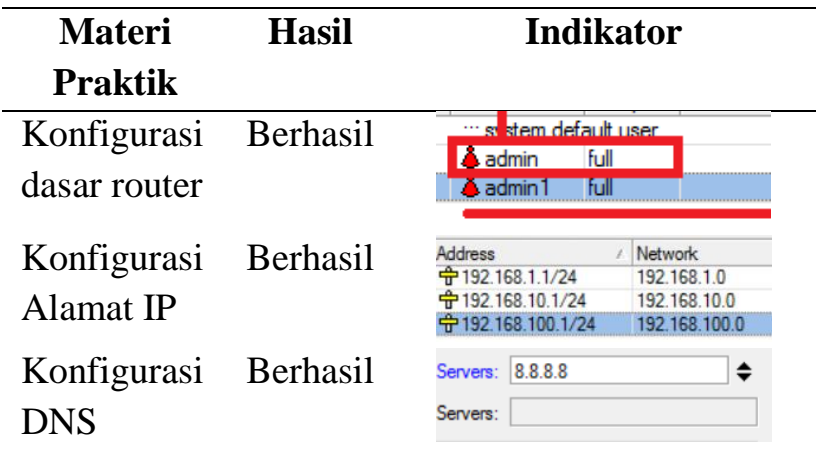

\section{\begin{tabular}{ll|l|l} 
Konfigurasi Berhasil & Routes & Nexhops Rules Vi
\end{tabular} \\ Routing \\ Statis

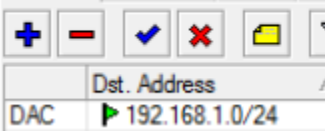

Konfigurasi Berhasi

Routing

Dinamis

Konfigurasi Berhasil

NAT

\section{Konfigurasi Berhasil DHCP}

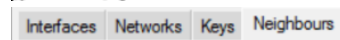

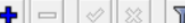

Address

P 192.168 .1 .1

Filter Rules NAT Mangle $\mathrm{S}$
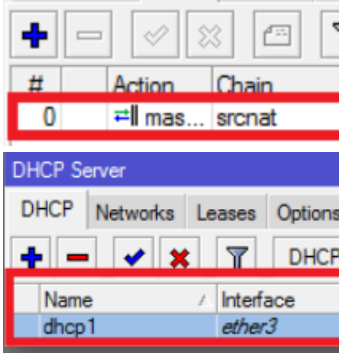

\section{- Uji Kelayakan}

Uji kelayakan media trainer dibagi menjadi 2 tahap, yaitu kelayakan kualitas materi dan kelayakan media. Masing-masing ditunjukkan pada tabel 6 , tabel 7 berikut :

Tabel 6. Uji Kelayakan Materi

\begin{tabular}{lcccc}
\hline \multicolumn{1}{c}{ Aspek } & Skor & $\begin{array}{c}\text { Rerata } \\
\text { Skor }\end{array}$ & $\begin{array}{c}\text { Prosentase } \\
(\boldsymbol{\%})\end{array}$ & $\begin{array}{c}\text { Prosentase } \\
\text { Total } \\
(\boldsymbol{\%})\end{array}$ \\
\hline $\begin{array}{l}\text { Knowledge } \\
\text { Quality }\end{array}$ & 4.41 & $\mathbf{4 . 4 7}$ & 88.2 & $\mathbf{8 9 . 4}$ \\
$\begin{array}{l}\text { Knowledge } \\
\text { Relevancy }\end{array}$ & 4.6 & & 92 & \\
\hline
\end{tabular}

Tabel 7. Uji Kelayakan Media

\begin{tabular}{lcccc}
\hline \multicolumn{1}{c}{ Aspek } & Skor & $\begin{array}{c}\text { Rerata } \\
\text { Skor }\end{array}$ & $\begin{array}{c}\text { Prosent } \\
\text { ase (\%) }\end{array}$ & $\begin{array}{c}\text { Prosentase } \\
\text { Total } \\
(\%)\end{array}$ \\
\hline Presentability & 3.71 & & 74.2 & \\
Efficiency & 4.2 & & 84 & \\
Flexibility & 4 & & 80 & \\
Reliability & 3.5 & $\mathbf{4 . 0 3}$ & 70 & $\mathbf{8 0 . 7}$ \\
Quality & 4.2 & & 84 & \\
Size Matcing & 4.3 & & 86.6 & \\
\hline
\end{tabular}

Gambar 6 dibawah ini adalah hasil prosentase

kelayakan media trainer dalam bentuk bagan. 


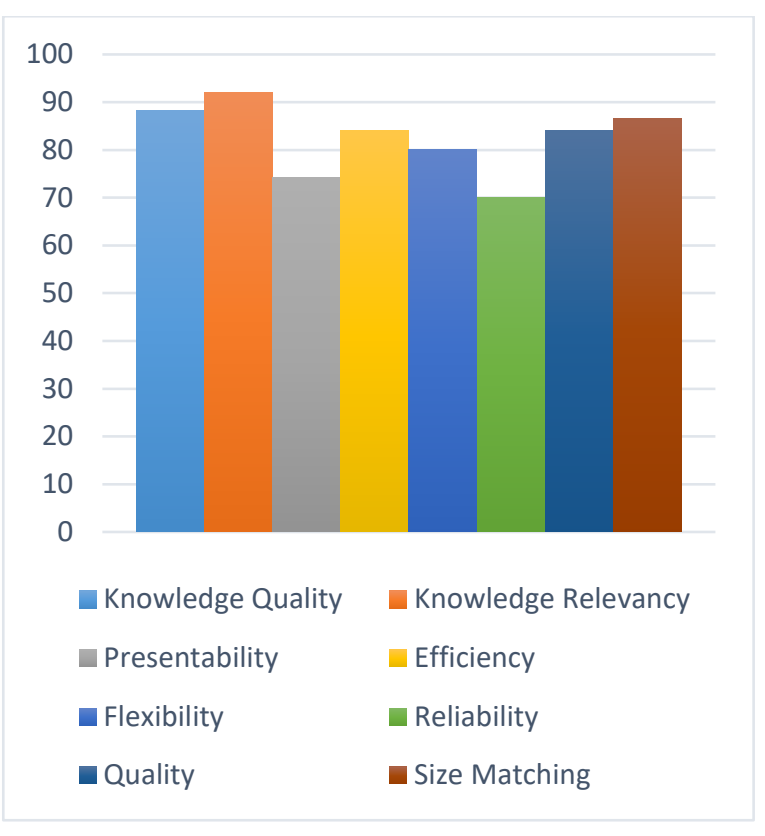

Gambar 6.Hasil Uji Kelayakan Media

Hasil uji fungsional menunjukkan bahwa setiap komponen dari trainer jaringan komputer bekerja dengan baik. Komponen tersebut dapat digunakan sebagai media pembelajaran untuk setiap kegiatan praktikum pada masing-masing pertemuan yang bersifat praktik, mulai dari konfigurasi dasar peralatan jaringan hingga troubleshooting. Hasil uji kelayakan menunjukkan bahwa dari aspek kualitas materi (knowledge) dan dari aspek media secara keseluruhan sangat layak. Pada pengujian tersebut diperoleh skor $89,4 \%$ dari uji kelayakan kualitas materi dan $80,7 \%$ dari uji kelayakan media.

Hasil tes menunjukkan bahwa trainer jaringan komputer dasar memiliki tingkat relevansi pengetahuan mencapai 92 persen dari hasil penilaian oleh praktisi jaringan komputer. Namun trainer ini memiliki kelemahan pada aspek reliability dan presentability. Kedua aspek tersebut mendapat $70 \%$ dan $74,2 \%$. Rendahnya nilai reliabilitas disebabkan oleh masing-masing komponen trainer tersebut belum terlindungi sehingga komponen keselamatannya dinilai kurang. Nilai kelayakan yang rendah ini disebabkan oleh tata letak kabel yang tidak begitu rapi, sehingga kabelnya harus diatur ulang.

\section{SIMPULAN}

Dari uji fungsional diketahui semua komponen bekerja dengan baik untuk setiap materi praktikum. Uji kelayakan media dan materi menunjukkan bahwa trainer jaringan komputer layak digunakan sebagai media praktikum. Kedua hasil uji kelayakan tersebut menunjukkan trainer jaringan komputer layak dijadikan sebagai suplemen untuk media belajar jaringan komputer dasar. Selain itu, trainer jaringan komputer dasar layak dan cocok untuk mahasiswa dengan tingkat pemahaman yang berbeda.

Hasil penelitian ini menunjukkan bahwa trainer jaringan komputer dasar memiliki beberapa kelemahan fisik karena belum terdapat pelindung terhadap device jaringan yang terpasang pada trainer. Untuk pengembangan lebih lanjut, media trainer ini dapat ditingkatkan melalui beberapa cara, antara lain dengan membuat versi portabel dengan dimensi yang lebih kecil, dan menambahkan pelindung pada network device yang terpasang.

Pengujian media trainer ini baru sebatas pada uji kelayakan media dan materi, dalam pengembangan lebih lanjut, diperlukan uji efektifitas media trainer ini jika digunakan dalam pembelajaran jaringan komputer. 


\section{DAFTAR PUSTAKA}

[1] Rahman, R. A., Hassan, A. \& Zan, H. H. 2015. On The Use of Animated Media in Communicating Abstract Concepts of Computer Networking: A Preliminary Survey. IEEE 7th International Conference on Engineering Education. Retrieve from ieeexplore.ieee.org

[2] Pernanda, D., Zaus, M. A., Wulansari, R., \& Islami, S. (2018, April). Effectiveness of instructional media based on interactive cd learning on basic network at vocational high school: improving student cognitive ability. In International Conferences on Educational, Social Sciences and Technology (pp. 443-447). Fakultas Ilmu Pendidikan UNP.

[3] Samad, M. R. (2017). Efektivitas Penggunaan Aplikasi Simulasi Cisco Packet Tracer pada Pembelajaran Instalasi Jaringan Komputer di SMK Negeri 5 Takalar (Doctoral dissertation, UNIVERSITAS NEGERI MAKASSAR).

[4] Ampriliambudi, T. P. (2017). Modul Pembelajaran Virtual LAN pada Cisco Packet Tracer untuk Meningkatkan Kompetensi Psikomotorik Siswa di SMK YPM 1 Taman. IT-Edu: Jurnal Information Technology and Education, 2(02).

[5] Lee, S. J., \& Reeves, T. C. (2017). Edgar dale and the cone of experience. Foundations of Learning and Instructional Design Technology.

[6] Arifin, Zaenal. 2005. Easy Way To Build Computer Network. Yogyakarya: Andi Offset.

[7] Fuada, S. (2016). Pembuatan Trainer Board Astable Multivibrator (AM) Sebagai Media Pembelajaran Pendidikan (Versi Elektronik). Jurnal Nasional Teknik Elektro, Vol. 05 No. 02. Diperoleh pada 09 Desember 2016, dari jnte.ft.unand.ac.id.

[8]Asyhar, Rayandra. 2012. Kreatif Mengembangkan Media Pembelajaran. Jakarta : Referensi Jakarta.

[9]Zukifli, C. Z. \& Suparmin, S. (2015). Wireless Communication Network Tools Kits with Visualization Techniques:Design Consideration for Proposed Architecture. International Journal of Multimedia and Ubiquitous Engineering, Vol. 10. No. 07. Retrieve from http://dx.doi.org.

[10] Siagian, S. 2014. Development of Basic Electronic Instructional Module and Trainer. European Journal of Computer Science and Information Technology, Vol. 02. No. 03. Retrieve from www. eajurnal.org.

[11] Khan, A \& Masood, M. 2013. The Design and Development of A Multimedia Assisted Mastery Learning Courseware in Learning of Cellular 
Respiration.Malaysia: Universiti Utara Malaysia.

[12] Por, F.P., \& Fong, S. F. 2011. The Design and Development of Multimedia Pronunciation Learning Management System. World Academy of Science, Enggineering And Technology, (60), 2004-2008.

[13] Riduwan. 2013.Skala Pengukuran Vaiabelvariabel Penelitian.Bandung:Alfabeta 